\title{
National standard research on the minimum allowable values of energy efficiency and energy efficiency grades for air cleaners
}

\author{
Huang Jin ${ }^{1,}$, Shen $\mathrm{Hao}^{2}$, Lin Ling ${ }^{1}$, Wang Kang ${ }^{2}$, Wang Baozhu ${ }^{3}$, Yang Xianfei ${ }^{4}$, Wu Wei ${ }^{5}$ Zhang Xiaoxin ${ }^{1}$,Li Zhenhai ${ }^{6}$ \\ ${ }^{1}$ China National Institute of Standardization, Beijing 100191, China \\ ${ }^{2}$ Shanghai Metrological Testing Technology Research Institute \\ ${ }^{3}$ Dongguan Yujie New Material Co., Ltd \\ ${ }^{4}$ Weikai Testing Technology Co., Ltd \\ ${ }^{5}$ Zhuhai Gree Electric Co., Ltd \\ ${ }^{6}$ Tongji University
}

\begin{abstract}
This paper demonstrates the background and the significance on the national standard research on the minimum allowable values of energy efficiency and energy efficiency grades for air cleaners. The study also introduces the general thinking and principle of the standard development the determination of the minimum allowable values of energy efficiency, the classification of the energy efficiency grades for air cleaners, as well as the testing methods, which would help to eliminate the production of the high energy consumption air cleaner products, and effectively improve their level of the energy efficiency through the developing and implementation of the national standard.
\end{abstract}

\section{Background and significance of developing national standards for minimum allowable values of energy efficiency and energy efficiency grades of air cleaners}

At present, China has introduced a series of energy conservation and environmental protection policies, systems, plans and standards to improve energy efficiency, control energy consumption and reduce pollutant emissions. Since the 1980 s, the country has successively formulated and implemented more than 70 mandatory performance standards for key energyconsuming products. Through the implementation of the standard, the energy efficiency of the end-use energy products has been improved, and high-energy consumption products have been phased out. At the same time, these standards have also promoted the advancement of energy-saving technologies, improved the level of energy-saving management, and promoted energy-saving and emission reduction.

As a health electrical product that professionally improves and solves indoor air pollutant, the air cleaner has been developed in China for more than 15 years. It could be used in living room, office, public places, industrial plants, hospitals and other indoor environment places. For one thing, people's health awareness is improving; for another thing, the cleaner has outstanding particulate matter removal ability and assists in microorganisms, gaseous pollution, formaldehyde and other removal functions. These make the cleaner from public cognition stage to recognition and be widely purchased stage. Especially after the smog and PM2.5 problems became severe from 2013, with the higher target requirements of national energy conservation and emission reduction targets for air pollutants such as dust particulates, air cleaner is one of the main environmental products among indoor air purification that plays an active and effective role in the control of indoor PM2.5, formaldehyde and VOC air pollutants, and it quickly becomes a special-purpose product that has entered thousands of households and is used as one of the daily household appliances.

After 2007, lots of domestic and foreign production and sales companies entered the air cleaner industry. Since 2010, the annual sales volume and annual sales of air cleaners in China have maintained a growth rate of more than $20 \%$, and the annual output has maintained a growth rate of more than $25 \%$ that shows a considerable industrial development speed, and its growth rate and the accompanying energy consumption amount cannot be ignored. To this end, there is an urgent need to develop relevant mandatory performance standards to regulate their energy consumption. Only in this way can we better regulate the market competition order of China's air cleaner products. These standards could improve the energy efficiency threshold to entry for air cleaners as well as support the implementation of the energy efficiency "leader" and environmental protection "leader" system. National standard research on the minimum allowable values of energy efficiency and energy efficiency grades for air cleaners is proposed by the National Development and Reform Commission, and jointly organized and developed by the National Energy Foundation and Management Standardization Technical

\footnotetext{
* Corresponding author: huangjin@cnis.gov.cn
} 
Committee (SAC/TC20) in conjunction with the National Environmental Protection Industry Standardization Technical Committee (SAC/TC275). The standard is included in the 2016 mandatory national standard revision plan.

\section{Development of National Standards for Minimum allowable values of energy efficiency and Energy efficiency grades of Air cleaners}

\subsection{Standard for formulation principle}

The national standards formulation for minimum allowable values of energy efficiency and energy efficiency grades of air cleaners should follow below principles:

- The standards should keep in line with national energy conservation and environmental protection policies, and closely combine with national industrial development policies;

- The standards should extensively reference related standards of domestic air cleaner to determine technical indicators, and coordinate and link with the current domestic standards, so that the energy efficiency standards and the above standards form a set of interconnected, interactive, complete standards series, and that can make the cleaner play an important role in the energy conservation supervision and management work; and it should be verified to ensure the scientific and operability of the test method;

- The standards should based on the standards level of foreign advanced industrial countries, try to be in line with relevant international standards and regulations to ensure the rationality and coordination of standards; and determine technical requirements according to industry status and advanced rules to ensure the technical requirements to be comprehensive, scientific and advanced and operational.

\subsection{Standard scope of application}

At present, the purification methods of the air cleaner mainly include the indoor air passing through the purifying component to achieve the cycle purification, the ion generation to achieve the diffusion purification, and the air to pass through the purification component to achieve a single purification, etc. The circulating purification method products are widely used in indoor pollutants control because of their high purification efficiency, reliable performance and technical stability. The purification theory, the use environment, the use method and the evaluation method and the circulation purification method of the diffusion purification method and the single purification method are different. Therefore, it's clarified that the scope of this standard is mainly for the air cleaner with the purification method that uses the purification components to achieve indoor air purification.
It's internationally recognized that contribution rate of particulate matter in environmental air pollutants is particularly prominent and it is more common and longterm than gaseous pollutants and microbial pollution. In China, atmospheric smog, PM2.5 and other particulate matter pollutants are particularly significant. Therefore, the purification capacity is the basic performance of air cleaners at home and abroad, and it is significantly stronger than the purification ability for gaseous pollutants or microorganisms. Therefore, this standard is for the air cleaners that have the purification function of certain particulate matter and can have the ability to purify gaseous pollutants.

This standard references the relevant provisions of GB/T 18801-2015 Air cleaner, and has made reasonable adjustment according to the current status of such products, and specifies that the air cleaners complying with the standard should have the clean air delivery rate of particle $50 \mathrm{~m} 3 / \mathrm{h} \sim 800 \mathrm{~m} 3 / \mathrm{h}$, that can cover the domestic indoor air cleaner with the largest domestic production, possession and demand, and can meet the requirements for testing and evaluation of such products.

In consideration of the domestic consumers demand for the purification performance of other pollutants, such as gaseous pollutants (including formaldehyde, toluene, TVOC) and microorganisms, the air cleaners that have certain particulate matter purification ability, as well as gaseous pollutant purification ability also meet the scope of this standard.

For air purification products that only apply ion generation technology, air purification equipment such as duct air purification devices, fresh air device, etc., air cleaners that only have gas pollutants and microbial purification capabilities, industrial, medical, vehicle, treatment, etc. special-purpose design, and those used in anti-corrosive and anti-explosive special environments all cannot apply the test requirements and methods of this standard due to the special requirements of their application environment and the differences in the way they are used. Therefore, this standard does not apply to those products mentioned in this section.

\subsection{Key terms and definitions}

This standard provides seven terms and definitions of rated condition, clean air delivery rate of particle, input power of purity, energy efficiency ratio, standby power, purification efficiency of gaseous pollutants and minimum allowable values of energy efficiency, among which:

- Energy efficiency ratio: the internationally recognized objective technical indicator of the energy saving capacity of an air cleaner is the ratio of clean air delivery rate of particle to input power of purity at rated condition, expressed by EER.

- Clean air delivery rate of particle: short name is clean air volume, that is an internationally recognized parameter for demonstrating the ability of air cleaners to purify particulate pollutants, and is also defined as the specification parameters of products. It indicates the rate at which the air cleaner provides clean air to estimate the 
effective room size of the product as a primary reference for consumers to purchase and use. It is calculated and tested under rated conditions and specified test conditions and is expressed in CADR.

- Input power of purity: The air cleaner mainly provides the function of purifying indoor air. However, with the multifunctional and humanized design of the product, more and more power-consuming components are generated. This standard only evaluates the energy efficiency of core functions to limit the development of such products, and it proposes the definition of input power of purity that specifically refers to the input power that is required to provide clean air delivery rate of particle at rated conditions, and use it as the basic energy consumption for the energy efficiency ratio assessment. It includes the input power of the motor, high-voltage electrostatic generator, ion generator, control and drive circuit and other electrical components that cannot be individually turned off; but not includes other functions that could be separable from air cleaner. Only consider the purification of particulate matter required input power, denoted by $\mathrm{P}$.

Purification efficiency of gaseous pollutants: it is used to judge the strength of the purification of gaseous pollutants possessed by air cleaners. According to the purification efficiency of gaseous pollutants, air cleaners can be classified into Class I and Class II products. The purification efficiency of gaseous pollutants is related to the effective room size of the air cleaner, and it's the parameter for the purification ability of gaseous pollutants after running at the equivalent test time of the calculation. It indicates the ideal purification efficiency for gaseous pollutants after the air cleaner is operated for 1 hour under the nominal effective room size condition and it is denoted by Q.

- Minimum allowable values of energy efficiency: it is the basic requirement for two basic energy efficiency related indicators such as air cleaner energy efficiency ratio and standby power. And it refers to the lower limit of the allowable energy efficiency ratio and the maximum standby power of the air cleaner under rated conditions and specified test conditions.

\subsection{Technical requirements for minimum allowable values of energy efficiency and energy efficiency grades}

- Product function classification. According to the market survey of air cleaners in China, the product models with both functions of purifying particulate matter and gaseous pollutants account for more than $90 \%$ of the total market. Considering the increase of the purification function of gaseous pollutants is to increase the corresponding filter components, the overall resistance of the air cleaner filter would increase, that would affect clean air delivery rate of particle and the motor power consumption, and then resulting the change in the energy efficiency ratio of the whole cleaner. Therefore, in the development of this standard, it is first proposed that divide the air cleaners into Class I and Class II products based on their purification efficiency of gaseous pollutants, and corresponding testing methods and definition principles are formulated. The Class I product refers to an air cleaner that only claims to have a particulate matter purification ability, or claims that it has purification abilities of any gaseous pollutants with measured efficiency less than 50\%; the Class II product refers to the cleaners that claim the ability of purifying both particulate matter and the gaseous pollutants and purification efficiency of any gaseous pollutants is not less than $50 \%$.

Specified energy efficiency ratio object. Air cleaner energy efficiency indicators that Energy Star performed are: EER is not less than $2.0 \mathrm{cfm} / \mathrm{W}$, equivalent to $3.4 \mathrm{~m}^{3} /(\mathrm{W} \cdot \mathrm{h})$, standby power is not greater than $2.0 \mathrm{~W}$, ozone generation amount is not more than $0.05 \mathrm{ppm}$ (equivalent to $5.0 \times 10-6 \%$ ). The energy efficiency indicator specified in GB/T 18801-2015 Air cleaner is the energy efficiency ratio (divided into the energy efficiency ratio of particulate matter and the energy efficiency ratio of gaseous pollutants). The energy efficiency ratio of the nominal different function air cleaners is not less than $2.00 \mathrm{~m}^{3} /(\mathrm{W} \cdot \mathrm{h})$ and $0.50 \mathrm{~m}^{3} /(\mathrm{W} \cdot \mathrm{h})$ respectively, and specified standby power is not more than $2.0 \mathrm{~W}$.

The removal of particulate matter is the most basic purification capability of air cleaners and the capability is widely available at home and abroad. And the energy efficiency ratio test and evaluation method of particulate matter is mature and reliable while the energy efficiency ratio requirements and test evaluation methods of gaseous pollutants are only proposed and used in China in the past two years. There has been a mixed reaction from all walks of life, and there is no basis for inclusion in mandatory performance standards. Therefore, this standard only specifies requirements for energy efficiency ratio of particulate matter.

- Determination of energy efficiency grades.Through the statistics of the energy efficiency ratio of particulate matter for 392 air cleaner types in the market, these types cover the mainstream models in the market, with a market share of over $80 \%$, accounting for about $40 \%$ of the total market model. The survey includes 130 brands of foreign brands and domestic brands. And they include 29 Class I products and 363 Class II products per function type; the technology types include filter type, electrostatic type, and composite type (filter type combined with electrostatic type).

A) Class I products

There are 29 types of Class I product, accounting for

$7.4 \%$ of the total models. According to the data provided by the manufacturer, the energy efficiency ratio of the particulate matters and the proportions are shown in Table 1.

Calculate according to national standard requirements in GB/T 24489-2009 General guidelines for the Preparation of Energy Efficiency Indicators for Energy Consumption Products, and then proceed statistical analysis. grade classification results for the energy efficiency ratio and standby power of Class I products are shown in Table 2. 
Table 1 Energy efficiency ratio results of Class I products

\begin{tabular}{cccc}
\hline $\begin{array}{c}\text { Energy efficiency } \\
\text { ratio of particulate } \\
\text { matter }\left[\mathrm{m}^{3} /(\mathrm{W} \cdot \mathrm{h})\right]\end{array}$ & $\begin{array}{c}\text { Quantity } \\
\text { (type) }\end{array}$ & Proportion & $\begin{array}{c}\text { Addition } \\
\text { ratio }\end{array}$ \\
\hline $\mathrm{EER} \geq 15.00$ & 2 & $6.90 \%$ & $6.90 \%$ \\
$14.00 \leq \mathrm{EER}<15.00$ & 0 & $0.00 \%$ & $6.90 \%$ \\
$13.00 \leq \mathrm{EER}<14.00$ & 0 & $0.00 \%$ & $6.90 \%$ \\
$2.00 \leq \mathrm{EER}<13.00$ & 2 & $6.90 \%$ & $13.79 \%$ \\
$11.00 \leq \mathrm{EER}<12.00$ & 1 & $3.45 \%$ & $17.24 \%$ \\
$10.00 \leq \mathrm{EER}<11.00$ & 3 & $10.34 \%$ & $27.59 \%$ \\
$9.00 \leq \mathrm{EER}<10.00$ & 4 & $13.79 \%$ & $41.38 \%$ \\
$8.00 \leq \mathrm{EER}<9.00$ & 1 & $3.45 \%$ & $44.83 \%$ \\
$7.00 \leq \mathrm{EER}<8.00$ & 1 & $3.45 \%$ & $48.28 \%$ \\
$6.00 \leq \mathrm{EER}<7.00$ & 3 & $10.34 \%$ & $58.62 \%$ \\
$5.00 \leq \mathrm{EER}<6.00$ & 5 & $17.24 \%$ & $75.86 \%$ \\
$4.00 \leq \mathrm{EER}<5.00$ & 2 & $6.90 \%$ & $82.76 \%$ \\
$3.50 \leq \mathrm{EER}<4.00$ & 1 & $3.45 \%$ & $86.21 \%$ \\
$3.00 \leq \mathrm{EER}<3.50$ & 1 & $3.45 \%$ & $89.66 \%$ \\
$\mathrm{E}<3.00$ & 3 & $10.34 \%$ & $100.00 \%$ \\
\hline
\end{tabular}

Table 2 Energy efficiency grade indicators for Class I products

\begin{tabular}{|c|c|c|}
\hline \multirow{2}{*}{$\begin{array}{l}\text { Energy } \\
\text { efficiency } \\
\text { grade }\end{array}$} & $\begin{array}{l}\text { Energy efficiency } \\
\text { ratio } \mathrm{m}^{3} /(\mathrm{W} \cdot \mathrm{h})\end{array}$ & \multirow{2}{*}{$\begin{array}{c}\text { Standby power } \\
\text { W }\end{array}$} \\
\hline & Class I & \\
\hline 1 & $E E R \geq 13.00$ & $\begin{array}{l}\leq 1.0 \text { (no } \\
\text { information or }\end{array}$ \\
\hline 2 & $10.00 \leq \mathrm{EER}<13.00$ & $\begin{array}{l}\text { status display } \\
\text { function) }\end{array}$ \\
\hline 3 & $3.50 \leq \mathrm{EER}<10.00$ & $\begin{array}{c}\leq 2.0 \text { (with } \\
\text { information or } \\
\text { status display } \\
\text { function) }\end{array}$ \\
\hline
\end{tabular}

The distribution of energy efficiency grades of the above-mentioned Class I products is shown in Figure 1.



Fig. 1 Energy efficiency ratio distribution of 29 Class I products
B) Class II products

There are 363 types of Class II products, accounting for $92.6 \%$ of the total models. According to the data provided by the manufacturer, the energy efficiency ratios of particulate matter are shown in Table 3.

Table 3 Energy efficiency ratio results of Class II products

\begin{tabular}{cccc}
\hline $\begin{array}{c}\text { Energy efficiency } \\
\text { ratio of particulate } \\
\text { matter }\left[\mathrm{m}^{3} /(\mathrm{W} \cdot \mathrm{h})\right]\end{array}$ & $\begin{array}{c}\text { Quantity } \\
\text { (type) }\end{array}$ & Proportion & $\begin{array}{c}\text { Addition } \\
\text { ratio }\end{array}$ \\
\hline $\mathrm{EER} \geq 15.00$ & 1 & $0.28 \%$ & $0.28 \%$ \\
$14.00 \leq \mathrm{EER}<15.00$ & 1 & $0.28 \%$ & $0.55 \%$ \\
$13.00 \leq \mathrm{EER}<14.00$ & 3 & $0.83 \%$ & $1.38 \%$ \\
$12.00 \leq \mathrm{EER}<13.00$ & 6 & $1.65 \%$ & $3.03 \%$ \\
$11.00 \leq \mathrm{EER}<12.00$ & 13 & $3.58 \%$ & $6.61 \%$ \\
$10.00 \leq \mathrm{EER}<11.00$ & 17 & $4.68 \%$ & $11.29 \%$ \\
$9.00 \leq \mathrm{EER}<10.00$ & 25 & $6.89 \%$ & $18.18 \%$ \\
$8.00 \leq \mathrm{EER}<9.00$ & 37 & $10.19 \%$ & $28.37 \%$ \\
$7.00 \leq \mathrm{EER}<8.00$ & 45 & $12.40 \%$ & $40.77 \%$ \\
$6.00 \leq \mathrm{EER}<7.00$ & 59 & $16.25 \%$ & $57.02 \%$ \\
$5.00 \leq \mathrm{EER}<6.00$ & 53 & $14.60 \%$ & $71.63 \%$ \\
$4.00 \leq \mathrm{EER}<5.00$ & 51 & $14.05 \%$ & $85.67 \%$ \\
$3.50 \leq \mathrm{EER}<4.00$ & 13 & $3.58 \%$ & $89.26 \%$ \\
$3.00 \leq \mathrm{EER}<3.50$ & 15 & $4.13 \%$ & $93.39 \%$ \\
$2.00 \leq \mathrm{EER}<3.00$ & 21 & $5.79 \%$ & $99.17 \%$ \\
$\mathrm{E}<2.00$ & 3 & $0.83 \%$ & $100.00 \%$ \\
\hline
\end{tabular}

Calculate according to national standard requirements in GB/T 24489-2009 and then proceed statistical analysis. Grade classification results for the energy efficiency ratio and standby power of Class II products are shown in Table 4.

Table 4 Energy efficiency grade indicators for Class II products

\begin{tabular}{|c|c|c|}
\hline \multirow{2}{*}{$\begin{array}{l}\text { Energy } \\
\text { efficiency } \\
\text { grade }\end{array}$} & $\begin{array}{c}\text { Energy efficiency ratio } \\
\mathrm{m}^{3} /(\mathrm{W} \cdot \mathrm{h})\end{array}$ & \multirow{2}{*}{$\begin{array}{l}\text { Standby } \\
\text { power W }\end{array}$} \\
\hline & Class II & \\
\hline 1 & $E E R \geq 11.00$ & $\leq 1.0$ (no \\
\hline 2 & $\begin{array}{l}8.00 \leq \mathrm{EER}<11.00 \\
3.50 \leq \mathrm{EER}<8.00\end{array}$ & $\begin{array}{l}\text { information } \\
\text { or status } \\
\text { display } \\
\text { function) }\end{array}$ \\
\hline 3 & & $\begin{array}{c}\leq 2.0 \text { (with } \\
\text { information } \\
\text { or status } \\
\text { display } \\
\text { function) }\end{array}$ \\
\hline
\end{tabular}

The distribution of energy efficiency grades of the above II products is shown in Figure 2. 


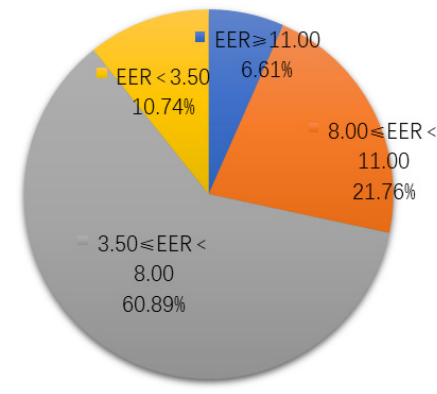

Fig. 2 Energy efficiency ratio distribution of 363 Class II products

- Determination of minimum allowable values of energy efficiency

The minimum allowable values of energy efficiency of air cleaner are defined as the energy efficiency ratio of $3.50 \mathrm{~m} 3 /(\mathrm{W} \cdot \mathrm{h})$ and the standby power $2.0 \mathrm{~W}$ of grade 3 in Tables 2 and 4. Based on the incomplete statistics of the current market product investigation, combined with the sales volume and model ratio of the listed/unlisted energy efficiency ratio statistical models, as well as the unqualified ratio of standby power, total minimum allowable values of energy efficiency (energy efficiency ratio and standby power) unqualified ratio is estimated to be around $15 \%$ to $20 \%$.

\subsection{Test and calculation methods}

This standard specifies the corresponding test and calculation methods for energy efficiency ratio (clean air delivery rate of particle, input power of purity), purification efficiency of gaseous pollutants, and standby power. Clean air delivery rate of particle, input power of purity and the standby power in the energy efficiency ratio are tested according to the methods specified in GB/T 18801-2015; the purification efficiency of gaseous pollutants is tested according to the method specified in the appendix, and is not detailed here.

The energy efficiency of the air cleaner is calculated according to equation (1), and the result retains two decimal places:

where:

$$
\mathrm{EER}=\mathrm{CADR} / \mathrm{P}
$$

EER - energy efficiency ratio, $\left[\mathrm{m}^{3} /(\mathrm{W} \cdot \mathrm{h})\right]$;

CADR - clean air delivery rate of particle, $\left(\mathrm{m}^{3} / \mathrm{h}\right)$;

$\mathrm{P}$ - input power of purity (W).

\section{Conclusion}

The national standard for energy efficiency limit and energy efficiency grade of air cleaner is another energy efficiency standard for environmental protection equipment for air pollutant control series developed by SAC/TC275 following the industrial dust collector energy efficiency limit value and national standard of energy efficiency grade. It will coordinate and implement in cooperation with the air cleaner standards, test method standards and high-performance air cleaner evaluation standards, which will help China's indoor air pollutant control, effectively increase product market access requirements, improve product energy efficiency, and reduce energy consumption; at the same time, it will also lead the technological advancement, encourage the production and consumption of environmental protection equipment to be energy-saving, high-efficiency and advanced; it will also help the government to strengthen the market supervision and management of air cleaner products, and support the implement of energy efficiency and environmental protection leader system in the future.

Author: Huang Jin

Researcher of the China National Institute of Standardization, Resources and Environment Branch, member of the National Environmental Protection Industry Standardization Technical Committee (SAC/TC275) and the National Environmental Management Standardization Technical Committee (SAC/TC207). He has been engaged in the research and development of standardization scientific research and important technical standards in the fields of environmental protection industry, environmental management and comprehensive utilization of resources. During the tenth Five-Year Plan, the Eleventh Five-Year Plan and the Twelfth Five-Year Plan period, he organized and developed more than 30 national standards for air pollutant control, water pollution control, solid waste treatment and disposal equipment were organized and developed, and is also responsible for the "Twelfth Five-Year" national science and technology support program "Development of industrial solid waste comprehensive utilization assessment technology and important standards", "Research and Application Demonstration of Technical Standards for Evaluation of Operation Performance of Major Environmental Equipment for Air Pollutants Control", "Key Industry Energy Saving and Emission Reduction Integrated Control Technology Research and Information Platform Development", etc. And lead more than 20 national standards draft work in the field of environmental management, and repeatedly won provincial and ministerial-level scientific research projects.

\section{References}

1. GB 4706.1 Household and similar electrical appliances-safty-part1: General requirements.

2. GB 4706.45 2008 Household and similar electrical appliances-safety-Particular requirements for aircleaning appliances.

3. GB/T 188012015 Air cleaner.

4. GB/T 188832002 Indoor Air Quality Standard.

5. H Jin, S Hao, L Wei, L Zhenhai, C Jun, W Wei, W Baozhu, Z Xiaoyu. Standard Science, 5(2017). 